\title{
Influence of right coronary artery shape on TIMI frame count and lesion distribution
}

\section{Influencia de la forma de la arteria coronaria derecha en el recuento de cuadros TIMI y la distribución de la lesión}

\author{
Mehmet S. Altintas*, Necip Ermis, Bilal Cuglan, Erdal Alturk, and Ramazan Ozdemir \\ Department of Cardiology, Inonu University, Faculty of Medicine. Malatya, Turkey
}

\begin{abstract}
Background: The shape of the right coronary artery (RCA) may vary between individuals. Objective: The aim of this study was to investigate whether the shape of RCA has any effect on TIMI frame count (TFC), TIMI flow score, and lesion distribution length in patients with ST-elevation myocardial infarction (STEMI) caused by RCA. Materials and methods: The angiograms of 163 patients who applied to our hospital with STEMI caused by the RCA were included in the study. TFC's were calculated. Results: The patients were divided into two groups according to the geometric shape of the RCA as C (124 pts, 101 males, mean age $66.1 \pm 12.3$ years) or $S$ (39 pts, 30 males, mean age $60.0 \pm 10.8$ years) based on the angiographic view from the left oblique position. Lesion location was significantly higher in the proximal and mid regions compared to the distal region in patients with $C-R C A(p<0.001)$. TFC was significantly higher in the S-RCA group $(p=0.0014)$. There was a statistically significant difference between the groups in terms of mean age of $p=0.003$. Conclusion: Lesion frequency was significantly higher in the proximal and mid regions in patients with C-RCA. TFC's were significantly higher in the S-RCA group. Longer S-RCA length compared to C-RCA and local shear stress characteristics may also explain these findings.
\end{abstract}

Key words: Right coronary artery. TIMI frame count. Coronary artery shape.

\section{Resumen}

Antecedentes: La forma de la arteria coronaria derecha puede variar entre los individuos. Objetivo: El objetivo de este estudio fue investigar si la forma de la arteria coronaria derecha (RCA) tiene algún efecto sobre el conteo de cuadros TIMI (TFC), el puntaje de flujo TIMI y la longitud de distribución de la lesión en pacientes con infarto de miocardio con elevación del ST (STEMI) causado por RCA. Material y métodos: Se incluyeron en el estudio los angiogramas de 163 pacientes que se aplicaron a nuestro hospital con STEMI causado por la arteria coronaria derecha. Se calcularon los TFC. Resultados: Los pacientes se dividieron en dos grupos según la forma geométrica de la arteria coronaria derecha como C (124 puntos, 101 masculino, edad media $66.1 \pm 12.3$ años) o S (39 puntos, 30 masculino, edad media $60.0 \pm 10.8$ años) según vista angiográfica desde la posición oblicua izquierda. La ubicación de la lesión fue significativamente mayor en las regiones proximales y medias en comparación con la región distal en pacientes con $C-R C A(p<0.001)$. TFC fue significativamente mayor en el grupo $S$ - $R C A$ $(p=0.0014)$. Hubo una diferencia estadísticamente significativa entre los grupos en términos de edad media de $(p=0.003)$.

\section{Correspondence:}

*Mehmet S. Altintas

E-mail: pirpirima21@gmail.com
Date of reception: 23-02-2020

Date of acceptance: 12-06-2020

DOI: 10.24875/ACME.M20000164
Available online: $27-10-2020$

Arch Cardiol Mex. 2020;90(4):439-443 www.archivoscardiologia.com 2604-7063 / @ 2020 Instituto Nacional de Cardiología Ignacio Chávez. Published by Permanyer. This is an open access article under the CC BY-NC-ND license (http://creativecommons.org/licenses/by-nc-nd/4.0/). 
Conclusión: La frecuencia de las lesiones fue significativamente mayor en las regiones proximales y medias en pacientes con C-RCA. Los TFC fueron significativamente más altos en el grupo S-RCA. Una mayor longitud de S-RCA en comparación con C-RCA y las características locales de tensión de corte también pueden explicar estos hallazgos.

Palabras clave: Arteria coronaria derecha. Conteo de cuadros TIMI. Forma de arteria coronaria.

\section{Introduction}

Besides known risk factors, atherogenesis is associated with hemodynamic factors such as increased and decreased flow velocity and disturbances in vascular system. These factors have been shown to be related with the geometric shape of the vessel'. Branching regions, bifurcation, and proximal portions of coronary arteries are more frequently affected than other regions ${ }^{2}$. McDaniel et al. showed that target lesions of ST elevation myocardial infarction (STEMI) were generally the proximal region of RCA, the proximal part of large curve, and just distal to the bifurcation, which create a turbulence of blood flow in the angiograms of patients undergoing cardiac catheterization due to STEMI ${ }^{3}$. The length, curve, and flow pattern of the right coronary artery (RCA) have been shown to be associated with development atherosclerosis in $\mathrm{RCA}^{4-7}$. The previous studies showed that the probability of having STEMI due to RCA was more frequent in patients with $C$ shaped $R C A^{3,8}$. However, the effect of the RCA shape on TIMI frame count (TFC), TIMI flow score, and lesion distribution length has not been evaluated in this patient group.

\section{Materials and methods}

This study was conducted between February 2010 and June 2012. We evaluated the angiograms of 163 patients who applied to the hospital with STEMI caused by the RCA. The patients were divided into two groups according to the geometric shape of the RCA as $C$ or $S$ based on the angiographic view from the left oblique position. In our study group, 124 patients had C-RCA and 39 had S-RCA. The study protocol was approved by the Ethics Committee of the Faculty of Medicine in Inonu University. The files of all patients were evaluated to obtain data such as age, gender, co-morbidities, risk factors, and laboratory results. The exclusion criteria included heart failure, cardiomyopathy, coronary artery bypass history, any previous intervention to RCA, artery diameter $<2 \mathrm{~mm}$, failing to pass the distal part of lesion, and the absence of an angiographic image to assess TFCs according to the Gibson method.

\section{Coronary angiographic evaluation}

The angiographic images of patients with femoral or radial access were examined, and the coronary angiography procedure was done using the "Philips Integris 5000 , Netherland" device. The evaluation was done by two-independent observers. The shape of RCA was determined by angiography from the left oblique position. Proximal region is defined as from the RCA ostium to the right ventricle branch; mid region is defined as from the right ventricular branch to the acute margin branch; and distal region is defined as after the acute margin branch. Arterial diameter measurements were done, and lesion region and length were determined from angiographic images. The "TFC" method of Gibson et al. was used to determine TFC after percutaneous intervention. The first frame includes the first opaque material seen in coronary artery ostium, and the last frame is the opaque material seen in the distal point of coronary artery. Distal point is described as the first branch of posterolateral artery for RCA. The difference between the first and the last frames was considered as the number of frames. We did not correct the frames by the length of the arteries. Interobserver variability was acceptable ranges (6.1\% for TFC).

\section{Statistical analysis}

Statistical analyses were performed using the SPSS software, version 17.0 (SPSS, Inc. Chicago, IL, USA). Continuous variables are presented as mean \pm standard deviation, and defined categorical variables are given as number and percentage. The Shapiro-Wilk normality test was used to test the normality of distribution of quantitative data. Differences between the variables of two groups were tested with the student's t-test or MannWhitney U-test when appropriate. The Chi-squared test was used to compare categorical variables. $P$ values below 0.05 were accepted as statistical significance.

\section{Results}

The study group consisted of a total of 163 patients undergoing primary percutaneous intervention who applied to the hospital with acute myocardial infarction 
Table 1. Demographic characteristics of patients

\begin{tabular}{|l|c|c|c|}
\hline & C shape (n = 124) & S shape (n = 39) & p value \\
\hline Age (year) & $66.1 \pm 12.3$ & $60.0 \pm 10.8$ & 0.003 \\
\hline DM & $31(25 \%)$ & $12(30.8 \%)$ & 0.476 \\
\hline Hyperlipidemia & $29(23.4 \%)$ & $8(20.5 \%)$ & 0.709 \\
\hline Smoking & $34(27.4 \%)$ & $12(30.8 \%)$ & 0.685 \\
\hline Gender & Men $101(81.5 \%)$ & Men $30(76.9 \%)$ & 0.535 \\
\hline & Women 23(\%18.5) & Women 9 $(\% 23.1)$ & \\
& & &
\end{tabular}

Table 2. TIMI frame count and laboratory findings of patient's group

\begin{tabular}{|l|c|c|c|}
\hline & $\begin{array}{c}\text { C shape } \\
(\mathbf{n}=124)\end{array}$ & $\begin{array}{c}\text { S shape } \\
(\mathbf{n}=39)\end{array}$ & $\begin{array}{c}\mathbf{p} \\
\text { value }\end{array}$ \\
\hline TIMI frame count (frame) & $12.4 \pm 5.3$ & $14.5 \pm 5.4$ & 0.014 \\
\hline White blood cell & $12.5 \pm 4.3$ & $11.6 \pm 3.7$ & 0,233 \\
\hline Hemoglobin (gr/dL) & $14.2 \pm 1.8$ & $13.6 \pm 1.7$ & 0.063 \\
\hline Hematocrit & $42.5 \pm 5.4$ & $41.0 \pm 5.2$ & 0.137 \\
\hline Mean platelet volume (fL) & $8.35 \pm 1.00$ & $8.13 \pm 0.74$ & 0.475 \\
\hline Mean corpuscular volume (fL) & $89.8 \pm 5.22$ & $91.75 \pm 5.26$ & 0.018 \\
\hline
\end{tabular}

resulting from $\mathrm{RCA} .124$ of the patients had $\mathrm{C}-\mathrm{RCA}$, while 39 had S-RCA. The baseline clinical characteristics of the patients in each group are summarized in table 1.

The mean age was $66.1 \pm 12.3$ years in the C-shaped group and $60.0 \pm 10.8$ in the S-shaped group. There was a statistically significant difference between the groups in terms of mean age $(p=0.003)$. There was no statistically significant difference between the groups in terms of gender, diabetes mellitus, hypertension, smoking, and hyperlipidemia. In addition, there was no statistically significant difference in terms of fasting blood glucose, BUN, creatinine, hemoglobin, hematocrit, white blood cell count, platelet count, and mean platelet volume (Table 2).

Lesion location was significantly higher in the proximal and mid regions compared to the distal region in patients with C-RCA ( $p<0.001)$. There was no statistically significant difference in the S-shaped group in terms of lesion location $(p>0.05)$. TFC was significantly higher in the S-RCA group compared to the C-RCA group $(p=0.0014)$ (Fig. 1). Considering lesion localizations, there was no difference between the groups in terms of proximal, mid, and distal segments $(p=0.116)$.

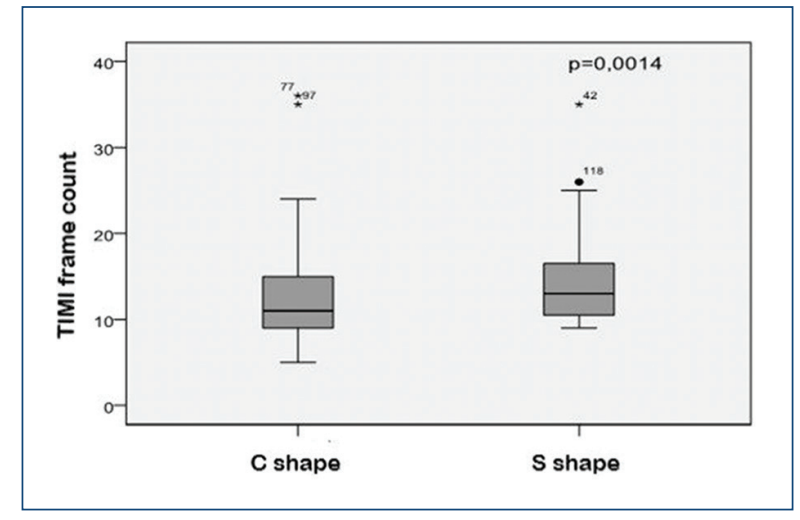

Figure 1. Comparison of TIMI frame count of patient's group

There was no statistically significant difference between TFCs in terms of having diabetes mellitus, smoking, hypertension, and hyperlipidemia ( $[p=0.799]$; $[p=0.975] ;[p=0.446]$; and [ $=0.214]$, respectively). Both groups were compared for the presence of other coronary artery lesions accompanying the RCA lesion. There was no statistically significant difference between the groups in terms of the presence of a left anterior descending (LAD), lesion or circumflex artery (Cx) lesion, and three vessel disease ( $[p=0.622]$; $[p=0.413]$; and $[p=0.682]$, respectively).

When the groups were compared in terms of lesion length, no statistically significant difference was found $(p=0.051 ; 19.36 \pm 8.23$ vs. $17.34 \pm 8.75)$. In addition, no statistically significant difference was found in terms of mean arterial diameter ( $p>0.05)$.

\section{Discussion}

Although atherosclerosis is usually localized, it is associated with systemic risk factors such as hypertension, smoking, and hyperlipidemia ${ }^{4,9-12}$. Some regions of coronary arteries such as coronary artery bifurcation, proximal portions, and branching regions are more affected than other locations ${ }^{2}$. Some researchers have suggested that these regions are prone to atherogenesis due to the impact of hemodynamic stress associated with anatomic variations in the arterial wall and local geometry in these regions ${ }^{13-22}$. Studies have shown the shape, flow pattern, and length of the RCA to be associated with the development of atherosclerosis ${ }^{4-7}$. In the current study, the frequency of lesions in the proximal and mid regions was significantly higher compared to the distal region. It has been shown that lesions in the 
proximal region of $\mathrm{C}$-shaped right coronary arteries are more prone to acute myocardial infarction due to their thin structure. McDaniel et al. suggested that turbulent flow may play an important role in the pathogenesis of acute coronary syndrome and the settlement of the culprit lesions in the proximal regions of the coronary artery $^{3}$. Sabbah et al. showed that the inner wall of the RCA had lower shear stress rate, while several autopsy studies have found these regions to have plaques with great intensity and severity ${ }^{23-25}$. In their study, Nwasokwa et al. investigated the relationship between thin coronary arteries and atherogenesis, and similar to our study, they suggested that having a thin coronary artery can be a risk factor for coronary atherosclerosis ${ }^{26}$. It is unclear how the diameter of coronary artery, which normally affects hemodynamics, influences the presence of atherosclerosis. Hemodynamic patterns such as increased blood flow, blood flow rate, and shear stress can accelerate the development of or suppress atherogenesis ${ }^{27}$. Endothelium is extremely sensitive to the shear stress, producing anti-atherogenic substances (e.g., nitric oxide). Low shear stress conditions are pro-atherogenic and lead to atherosclerotic plaque formation. Shear stress also influences the activation of endothelial cells through multiple mechanisms that target mitogen-activated protein kinases, nuclear factor-kappa-B, and endothelial nitric oxide synthase. Low shear stress can trigger intracellular cascades and shift phenotypic endothelial cell expression to an atherosclerotic prone state ${ }^{28}$. In their experimental study, Qiu et al. ${ }^{29}$ showed higher numbers of intraplaque microvessels in the high shear stress region and abnormal ECs in the microvessels in the plaque with membrane blebs, intracytoplasmic vacuoles, and leukocyte infiltration. In addition, in the present study, the rate of $\mathrm{Ml}$ in the mid region was statistically higher compared to the distal region of RCA. However, there was no statistically significant difference between S-shaped RCA regions in terms of lesion frequency. A few studies have examined the relationship between RCA and other coronary arteries in terms of frequency and severity of lesions ${ }^{8,30}$. Demirbağ et al. evaluated the coronary artery severity of patients according to the gensini score and found that C-RCA patients had significantly higher scores compared to S-RCA patients with no difference in terms of risk factors. In multivariate analyses, two or three vessel diseases were more common in patients with C-RCA, while the possibility of normal coronary artery angiogram was higher in patients with $\mathrm{S}-\mathrm{RCA} \mathrm{A}^{8}$. In this study, there was no statistically significant difference in terms of accompanying LAD or Cx coronary artery lesions
( $p=0.62$ and $p=0.41$, respectively). Similarly, there was no significant difference in terms of $L A D$ and $C x$ lesions existing together $(p=0.68)$. This difference was thought to be due to all the enrolled patients having STEMI. Previously, the relationship between the presence of coronary artery disease and the shape of coronary artery was partially explained by some theories based on factors such as hemodynamics, arterial geometry, blood velocity, and shear stress ${ }^{5,28,31-34}$. It has been reported that there was a substantial relationship between the short elongation of RCA and atherosclerosis ${ }^{4}$. Another study has shown that longer arterial segments had larger diameters ${ }^{35}$. As C-RCA has a smaller diameter, it has an increased risk of atherogenesis due to effect of a smaller diameter on inner hemodynamics. In this study, TFCs were significantly higher in the S-RCA group. This may be associated with longer durations of S-RCA compared to C-RCA, as mentioned by previous studies. However, our study had several limitations. Factors that may affect TFCs and cause acute coronary events, such as plaque morphology, length of the arteries, and unknown plaque contents, were undetermined during the study. Corrected TFC did not calculate. Finally, intracoronary thrombus burden was not measured.

\section{Conclusion}

In patients with acute myocardial infarction, lesion frequency was significantly higher in the proximal and mid regions in patients with C-RCA, which may be explained by local shear stress characteristics. There was no statistically significant difference in the S-RCA group in terms of lesion localization. TFCs were significantly higher in the S-RCA group compared to the C-RCA group, which is thought to be due to the longer duration of S-RCA.

\section{Funding}

This research has not received any private donations from public, commercial, or nonprofit organizations.

\section{Conflict of interests}

The authors report no competing interests.

\section{Ethical disclosures}

Protection of human animal and subjects: The authors declare that no experiments were performed on humans and animals for this study. 
Confidentiality of data: The authors declare that they have followed the protocols of their work center on the publication of patient data.

Right to privacy and informed consent: The authors declare that no patient data appear in this article.

\section{References}

1. Chien S. Significance of macrorheology and microrheology in atherogenesis. Ann NY Acad Sci. 1976;275:10-27.

2. Krams R, Wentzel JJ, Oomen JA, Vinke R, Schuurbiers JC, de Feyter PJ et al. Evaluation of endothelial shear stress and 3D geometry as factors determining the development of atherosclerosis and remodeling in human coronary arteries in vivo. Combining 3D reconstruction from angiography and IVUS (ANGUS) with computational fluid dynamics. Arterioscler Thromb Vasc Biol. 1997;17:2061-5.

3. McDaniel MC, Galbraith EM, Jeroudi AM, Kashlan OR, Eshtehardi P, Suo J, et al. Localization of culprit lesions in coronary arteries of patients with ST-segment elevation myocardial infarctions: relation to bifurcations and curvatures. Am Heart J. 2011;161:508-15.

4. Dvir D, Kornowski R, Gurevich J, Orlov B, Aravot D. Degrees of severe stenoses in sigma shaped versus C-shaped right coronary arteries. Am J Cardiol. 2003;92:294-8.

5. Kirpalani A, Park H, Butany J, Johnston KW, Ojha M. Velocity and wall shear stress patterns in the human right coronary artery. J Biomech Eng. 1999;121:370-5

6. Myers JG, Moore JA, Ojha M, Johnston KW, Ethier CR. Factors influencing blood flow patterns in the human right coronary artery. Ann Biomed Eng. 2001;29:109-20.

7. Dvir D, Kornowski R, Ben-Gal T, Berman M, Vidne B, Aravot D. Relation of amounts of narrowing to the length of the right coronary artery. Am J Cardiol. 2002;90:46-8.

8. Demirbag R, Yilmaz R. Effects of the shape of coronary arteries on the presence, extent, and severity of their disease. Heart Vessels. 2005;20:224-9.

9. Nerem RM, Cornhill JF. Hemodynamics and atherogenesis. Atherosclerosis. 1980;36:151-7.

10. Malek AM, Alper SL, Izumo S. Hemodynamic shear stress and its role in atherosclerosis. JAMA. 1999;282:2035-42.

11. Gimbrone MA Jr. Vascular endothelium: an integrator of pathophysiologic stimuli in atherosclerosis. Am J Cardiol. 1995;75:67B-70B.

12. Nerem RM, Alexander RW, Chappell DC, Medford RM, Varner SE Taylor WR. The study of the influence of flow on vascular endothelial biology. Am J Med Sci. 1998;316:69-75.

13. Giddens DP, Zarins CK, Glagov S. The role of fluid mechanics in the localization and detection of atherosclerosis. J Biomech Eng. 1993;115:588-4.

14. Friedman $\mathrm{MH}$. A biologically plausible model of thickening of arterial intima under shear. Arteriosclerosis. 1989:9:511-2.
15. Nerem RM. Vascular fluid mechanics, the arterial wall, and atherosclerosis. J Biomech Eng. 1992;114:274-82.

16. Fry DL. Acute vascular endothelial changes associated with increased blood velocity gradients. Circ Res. 1968;22:165-97.

17. Ross R. Atherosclerosis: a question of endothelial integrity and growth control of smooth muscle. Harvey Lect. 1981;77:161-82.

18. Nguyen ND, Haque AK. Effect of hemodynamic factors on atherosclerosis in the abdominal aorta. Atherosclerosis. 1990;84:33-9.

19. Friedman MH, Brinkman AM, Qin JJ, Seed WA. Relation between coronary artery geometry and the distribution of early sudanophilic lesions. Atherosclerosis. 1993;98:193-9.

20. Friedman MH, Baker PB, Ding Z, Kuban BD. Relationship between the geometry and quantitative morphology of the left anterior descending coronary artery. Atherosclerosis. 1996;125:183-92.

21. Fisher M, Fieman S. Geometric factors of the bifurcation in carotid atherogenesis. Stroke. 1990;21:267-71.

22. Kronzon I, Deutsch P, Glassman E. Length of the left main coronary artery: its relation to the pattern of coronary arterial distribution. Am J Cardiol. 1974;34:787-9.

23. Sabbah HN, Khaja F, Brymer JF, Hawkins ET, Stein PD. Blood velocity in the right coronary artery: relation to the distribution of atherosclerotic lesions. Am J Cardiol. 1984;53:1008-12.

24. Fox B, James K, Morgan B, Seed A. Distribution of fatty and fibrous plaques in young human coronary arteries. Atherosclerosis. 1982;41:337-47.

25. Fukumoto $Y$, Hiro T, Fujii T, Hashimoto G, Fujimura T, Yamada J, et al. Localized elevation of shear stress is related to coronary plaque rupture: a 3-dimensional intravascular ultrasound study with in vivo color mapping of shear stress distribution. J Am Coll Cardiol. 2008:51:645-50.

26. Nwasokwa ON, Weiss M, Gladstone C, Bodenheimer MM. Effect of coronary artery size on the prevalence of atherosclerosis. Am J Cardiol. 1996;78:741-6.

27. Zarins CK, Bomberger RA, Glagov S. Local effects of stenoses: increased flow velocity inhibits atherogenesis. Circulation. 1981;64:Il221-7.

28. Jenei $C$, Balogh E, Szabó GT, Dézsi CA, Kőszegi Z. Wall shear stress in the development of in-stent restenosis revisited. A critical review of clinical data on shear stress after intracoronary stent implantation. Cardiol J. 2016;23:365-73.

29. Qiu J, Lei D, Hu J, Yin T, Zhang K, Yu D, et al. Effect of intraplaque angiogenesis to atherosclerotic rupture-prone plaque induced by high shear stress in rabbit model. Regen Biomater. 2017;4:215-22.

30. Glagov S, Zarins C, Giddens DP, Ku DN. Hemodynamics and atherosclerosis. Insights and perspectives gained from studies of human arteries. Arch Pathol Lab Med. 1998;112:1018-31.

31. Gensini GG. A more meaningful scoring system for determining the severity of coronary heart disease. Am J Cardiol. 1983;51:606.

32. Lee BK, Kwon HM, Hong BK, Park BE, Suh SH, Cho MT, et al. Hemodynamic effects on atherosclerosis-prone coronary artery: wall shear stress/rate distribution and impedance phase angle in coronary and aortic circulation. Yonsei Med J. 2001;42:375-83.

33. Weydahl ES, Moore JE. Dynamic curvature strongly affects wall shear rates in a coronary artery bifurcation model. J Biomech. 2001:34:1189-96.

34. Friedman $\mathrm{MH}$. Some atherosclerosis may be a consequence of the normal adaptive vascular response to shear. Atherosclerosis. 1990;82:193-6.

35. Zhou Y, Kassab GS, Molloi S. On the design of the coronary arterial tree: a generalization of murray's law. Phys Med Biol. 1999;44:2929-45. 